\title{
Técnica, Esporte, Rendimento
}

\begin{abstract}
Para Valter Bracht
Uma das questões que com maior força parecem ainda afligir aqueles que se relacionam com o esporte, diz respeito aos debates que, nas últimas décadas, se : ocuparam em condená-lo e defende-lo. O esporte, : esse fenômeno social tão marcante do século passado, : e que continuará sendo, ao que parece, uma das : expressões desse nosso tempo, foi e continua sendo : alvo de reflexão, análise e questionamento, tanto no " campo mais restrito da Educação Física/Ciências do : Esporte, quanto, em um âmbito mais geral, nas : Ciências Humanas e Sociais.
\end{abstract}

Essas questões, que se colocam justamente porque o esporte é um fenômeno social rico e multifacetado, : e que não escaparam de grandes pensadores: contemporâneos, oxigenaram os debates da Educação : Física/Ciências do Esporte, mas foram também, inevitavelmente, fonte de diferentes mal-entendidos, : mal-estares e dissabores. O debate acadêmico nem : sempre foi tranqüilo, também porque ao questionar : o esporte, ele colocou sob suspeita (moral?, política?) : aqueles que se ocupavam com sua prática, : desestruturando uma das mais fortes fontes de : identidade dos professores e professoras de Educação : Física.

Nas próximas páginas ocupo-me de algumas questões : que se relacionam ao tema, considerando um campo teórico, a Teoria Crítica do Esporte, mas com especial : atenção a um ponto que me parece fundamental, : talvez insuficientemente discutido. Refiro-me à questão : da técnica, objeto de dúvidas, equívocos e mal- : entendidos, como recentemente foi destacado, ${ }^{1}$ mas : cuja importância conceituai, sobretudo para : entendermos o espírito do nosso tempo, está, segundo : penso, fora de dúvidas.
Alexandre Fernandez Vaz*

Considero em minhas observações, evidentemente, a técnica como meio propriamente dito, fundamental para o esporte e para várias de nossas atividades cotidianas. Refiro-me a ela também, no entanto, também como estrutura modelar, que fascina seu criador e que organiza vários modos de ser do mundo contemporâneo.

Meu texto se divide em três partes. Na primeira delas apresento alguns comentários a respeito da crítica ao esporte na Educação Física/Ciências do Esporte, considerando, como pano de fundo, as contribuições da Teoria Crítica do Esporte. Nesse contexto, levanto alguns aspectos de teorias que concorrem com ela, notadamente a Sociologia Figuracional de Norbert Elias e as contribuições de Roberto DaMatta sobre o futebol brasileiro. Na segunda parte do trabalho, procuro aprofundar a questão da técnica, tendo como referência principal o esporte, entendido como uma das formas de mediação entre o ser humano e seu próprio corpo, de organização da corporeidade. Retomo aqui considerações já parcialmente apresentadas em outros momentos. ${ }^{2}$ Por fim, na terceira parte, rediscuto a questão da técnica, tentando, a partir dos pontos de tensão até então expostos, elaborar algumas considerações sobre sua onipresença em ambientes que, em princípio, estão mais distantes do esporte de rendimento, como as quadras e pátios escolares.

A inspiração para este trabalho, implícita e explícita, como se verá, vem da obra de Theodor W. Adorno, um importante filósofo do século vinte, crítico da modernidade e do esclarecimento (Aufklárung), herdeiro da melhor tradição dialética. Foi também ele uma das referência fundamentais da Nova Esquerda dos anos sessenta e setenta, também no que se refere à contribuição que ela nos ofereceu a respeito do esporte. 


\section{CRÍTICA E MAL-ENTENDIDOS}

Uma das críticas mais duras que o esporte sofreu, tem origem na constatação de que seria ele, com suas : técnicas e regras, uma forma de domínio do corpo e : de suas expressões, o que, por sua vez, estaria : relacionado com o predomínio da ordem econômico- : social capitalista. Esporte e conservadorismo pareciam : ser parte um do outro, e há mesmo razões em número : suficiente, em diferentes épocas e lugares, para : corroborar essa idéia.

Veio se somar a essa crítica um outro elemento, : vincado na ponderação - ou mesmo na assertiva - : de que seria problemática a vinculação do esporte : com a ciência, porque ela estaria estruturada por uma : perspectiva equivocada, o "positivismo", ou porque : a própria ciência, seja ela qual for, seria sinônimo de : dominação e destruição.

No primeiro caso, o "positivismo" (com o qual : freqüentemente são confundidas as pesquisas : experimentais) deveria ser substituído pelo: "materialismo histórico", visão social de mundo que : seria privilegiada, porque transformadora e vinculada : aos interesses dos subalternos. No segundo caso, : quando a própria ciência é questionada, no que se : convencionou chamar de crise da modernidade, tratar- : se-ia de substituí-la como epicentro e critério de : verdade (até porque talvez não houvesse mais tal : critério), ou, pelo menos, reestrutura-la sob outras : bases.

Há, de fato, muito cientificismo na Educação : Física/Ciências do Esporte, expresso também, no : entanto, quando se procura entronizar o "materialismo : histórico" como estrutura para os critérios de verdade. : Por outro lado, não se pode deixar de ponderar a : necessidade de certo grau de universalidade, : justamente para ajudar a balizar os limites éticos do : agir humano. A ciência não é, quando vista de forma : isolada e sem que se considere seu momento de : dominação, uma boa referência para a ética, mas pode : nos auxiliar a pensar, entre outros pontos, a tensão entre particularidade e universalidade. Considero esse : um ponto fundamental, um avanço moderno do : melhor Esclarecimento (Aufklärung), uma vez que : nos possibilita seguir pensando numa ética que respeite e valorize as diferenças, mas que continue apostando em direitos universais. Além disso, continuo pensando nos ganhos do pensamento científico mesmo dele desconfiando e sabendo de sua dimensão destrutiva -, que ajuda a dirimir a presença e os efeitos dos muitos obscurantismos que nos rondam com insistência.

Como se pode ver, o emaranhado é complexo, com idéias cuja coexistência nem sempre é das mais tranqüilas, como aliás é comum quando o debate é animado pela política.

\section{Crítica, Contexto, Nova Esquerda}

A crítica ao esporte de rendimento, à exigência ou valorização do mais alto desempenho nas práticas esportivas, popularizou-se no Brasil nos anos oitenta e noventa, e tem origem em uma configuração histórica que tem como um de seus pontos fundamentais a divulgação das reflexões da New Left sobre o tema. Esse movimento, de origem sobretudo européia, e que em algum momento tomou o esporte como tema em sua crítica radical à sociedade administrada, condenou a presença do princípio do desempenho no esporte, ou ainda o próprio esporte, por ser vetor daquele princípio. A Teoria Crítica do Esporte provocou, com contribuições de estudiosos como Bero Rigauer e JeanMarie Brohm, ${ }^{3}$ entre outros, um enorme impacto na cena acadêmica européia - e parcialmente também da América do Norte - no final dos anos sessenta e início dos setenta do século passado.

A grande notoriedade e enorme impacto se devem, entre outras razões, ao contexto da época, que remete não só à contestação estudantil, mas à importância da Escola de Frankfurt - representada, nesse caso, sobretudo por Herbert Marcuse e Theodor Adorno, mas também por Jürgen Habermas - e a autocrítica que, na República Federal da Alemanha, se fazia ao recente passado nazista, marcado, também, pelos Jogos Olímpicos de Berlim, em 1936. A notoriedade se deve, também, à dura oposição que o movimento crítico sofreu de importantes e conhecidos teóricos do esporte, como Hans Lenk. ${ }^{4}$

A crítica que a Nova Esquerda empreendeu ao esporte, em que pese os eventuais equívocos - aos olhos de 
hoje talvez mais facilmente observáveis - procurou seguir, ao contrário do que se ouve aqui e ali, a melhor tradição ilustrada, e empreendeu esforços no sentido de exercer a negação determinada, e não a simples denegação do esporte. Vale dizer ainda, que, pelo menos parcialmente, a Nova Esquerda retoma e atualiza críticas que o movimento operário alemão já havia feito ao esporte, nas décadas de vinte e trinta do mesmo século.

Em linhas muito gerais, a Teoria Crítica do Esporte procura mostrar a correspondência estrutural e a identificação conceituai entre esporte e trabalho, sobretudo no que se refere aos processos de racionalização. $\mathrm{O}$ trabalho junto à linha de produção seria uma imagem correspondente àquele do atleta submetido aos princípios do treinamento esportivo, às repetições coordenadas das calculadas cargas de esforço. ${ }^{5}$ Nesse contexto, poderia ser dito que o esporte reproduz a lógica do trabalho, reforçando seu caráter de mercadoria, de reificação e de disseminador de ideologia. Além disso, seria ele repressivo, canalizando energias pulsionais potencialmente libertadoras, para fins que perpetuariam a dominação individual e de classe. $^{6}$

Esse debate, depois de perder força nos anos oitenta, parece ter ficado, desde a década passada, relegado à história das idéias. Contribui para isso, evidentemente, o refluxo do exercício da crítica sem concessões e das grandes narrativas nas Ciências Humanas e Sociais, movimento que, até certo ponto, acompanhou a derrocada do socialismo burocrático. É curioso esse processo, principalmente porque a Nova Esquerda se notabilizou pela crítica - que talvez devesse ter sido, no caso do esporte, mais contundente - ao socialismo burocrático. Sempre esteve claro que o esporte, nos países que compunham Pacto de Varsóvia, não era menos instrumental, vinculado ao rendimento ou totalitário do que aquele que se realizava nos países capitalistas.

Talvez valha a pena abrir um parêntese nessa reflexão, para chamar a atenção para uma questão que se torna importante ao comentarmos as relações entre esporte, socialismo e capitalismo. É preciso que se destaque o papel que os países do pacto de Varsóvia, especialmente as extintas União Soviética e República Democrática Alemã, tiveram no desenvolvimento do treinamento de alto rendimento esportivo.

Sempre houve, nesses países, uma enorme fascinação com o avanço tecnológico, algo aliás muito presente, mas não sem exceções, no marxismo. Essa fascinação encontrou eco na escalada armamentista, nos enormes investimentos na corrida espacial, na procura de grandes resultados esportivos. Lembro esse processo para reafirmar que não se trata, nesse caso, de opor capitalismo a socialismo, mas de considerar o esporte, e o treinamento corporal a ele vinculado, como expressões de nossa modernidade, em várias de suas versões.

Por outro lado, foi de enorme importância naqueles países, paradoxalmente, a idéia de amadorismo ligada aos ideais olímpicos, o que ajudava a forçar os países capitalistas, mesmo com dificuldades, a também mantê-la. O ideário do amadorismo acaba, em grande parte, naufragando no final dos anos oitenta e início dos noventa, juntamente com a derrocada do socialismo burocrático.

Longe de significar uma simples proteção dos ideais olímpicos, o amadorismo exercia, de forma algo invertida ao movimento que lhe deu origem, uma força ideológica importante no ideário dos países do leste. Em um conhecido manual de treinamento de atletismo da República Democrática Alemã, destaca-se a defesa do internacionalismo proletário e da amizade com a União Soviética, além da necessidade se enfrentar o "capitalismo monopolista", sobretudo o da República Federal da Alemanha, cuja "utilização" do esporte nos Jogos Olímpicos teria caráter imperialista. ${ }^{7}$

Também foram as contribuições desses países que ajudaram a marcar, com muita força, a idéia de uma educação moral, da formação de um "melhor caráter" por meio do esporte. Cito, como exemplo, a partir do mesmo manual referenciado no parágrafo anterior, na tradução portuguesa, relativamente conhecida por treinadores de atletismo brasileiros:

"Por fim, estas actividades - tanto no treino como na competição - são um meio de desenvolvimento da 
força de vontade dos jovens e de modelação do seu " caracter. O comportamento dos atletas nos treinos : e nas competições dá aos instrutores desportivos : boas oportunidades para ministrar também educação : moral e política. Sob a sua orientação, e com o auxílio : dos companheiros, os jovens têm a oportunidade de : enriquecer qualidades como: coragem, decisão, força : de vontade, perseverança, autodisciplina, lealdade, : espírito colectivista e prontidão." 8

\section{Especificidades e Paradoxos: Crítica Brasileira, Dilema Brasileiro, figurações}

No Brasil, a Teoria Crítica do Esporte foi divulgada e aprofundada, principalmente, por trabalhos de Kátia : Brandão Cavalcanti eValter Bracht. ${ }^{9}$ Eles se juntaram : a outros estudiosos brasileiros, animados por diversas : perspectivas críticas, e que tiveram uma forte influência : das Ciências da Educação, fenômeno mais raro na : Teoria Crítica do Esporte européia, mas presente, : em maior ou menor grau, também em Cavalcanti e : Bracht.

Curioso é notar que este debate esteve bastante, " circunscrito à Educação Física/Ciências do Esporte, " uma vez que no registro das Ciências Sociais emergiu : uma outra perspectiva. ${ }^{10}$ Desde o final dos anos setenta o : antropólogo Roberto DaMatta ${ }^{11}$ desenvolve um : corpo teórico que procura entender o dilema : brasileiro, ou, em outras palavras, o que faz do brasil, : Brasil. Nesse processo, encontra um lugar privilegiado : o papel desempenhado pelo esporte, especificamente : o futebol. Ao contrário do que diziam e ainda dizem : os críticos do esporte-espetáculo, DaMatta atribui a : ele, em especial ao futebol, um alto grau de : positividade, vinculado ao seu caráter de experiência : democrática e de promoção de unidade e identidade : nacionais, algo que, segundo diz, pouco se pode : observar em outras esferas da vida nacional. ${ }^{12} \mathrm{O}$ futebol : não é, diz DaMatta, "ópio do povo", ${ }^{13}$ mas um "drama : de justiça social".

Destaco as contribuições de DaMatta não só pelo " contraponto que apresentam em relação às oriundas da Nova Esquerda, mas também por conta de suas afinidades com a Sociologia Figuracional, de Norbert : Elias, cuja influência no campo da Educação : Física/Ciências do Esporte vem crescendo no Brasil.
Essa perspectiva sociológica, de alguma forma, também concorre com as da Nova Esquerda, seja porque problematiza as questões de um outro modo, seja porque é menos politizada, afrouxando as amarras que nos impõe a vontade política. Destaque-se que o debate entre a Sociologia Figuracional e a Teoria Crítica do Esporte tem sido levado adiante na cena acadêmica contemporânea, ainda que, como já foi dito, esta última perspectiva seja, nos dias de hoje, considerada, na maior parte das vezes, como datada e superada. ${ }^{15}$

Permito-me, rapidamente, mais três parágrafos sobre a relação entre a Sociologia Figuracional e as contribuições de DaMatta.

Com algum cuidado, talvez se possa dizer que o drama, como estrutura permanente e que se repete, é uma forma de compreender, de tematizar complexas configurações sociais modernas. DaMatta e Elias aproximam-se no que se refere ao peso que ambos atribuem à estrutura. Ao primeiro interessa aquilo que permanece, as semelhanças entre os fenômenos sociais, o que o autoriza, por exemplo, a falar do carnaval como uma festa única, ainda que com diferenças significativas em suas manifestações regionais. $^{16}$

Em Elias também a estrutura é fundamental, mas em sentido algo diferente do que para DaMatta, para o qual o drama social representa um momento, uma síntese da vida cotidiana, problematizando-a, apresentando novos caminhos, revelando e escondendo. Elias empreende sua metodologia de análise a partir das configurações, estruturas ou padrões mais ou menos estáveis, formados por cadeias de interdependências cada vez mais complexas, que se referem a entrelaçamentos racionais, porém imprevisíveis, envolvendo a dinâmica social e a modelação do aparato pulsional. ${ }^{17}$ Lembre-se, novamente, que essas mudanças envolvidas na interdependência dos indivíduos (ou pessoas, diria DaMatta) obedecem a uma dinâmica não planejada, mas que tem direção observável, segundo Elias, desde os tempos mais remotos da civilização. ${ }^{18}$

Talvez a diferença fundamental seja a de que os tipos 
de civilização e modernidade predicados por DaMatta : tenham um componente diferente, pensado desde a : periferia da modernidade, na especificidade brasileira. : É um componente lúdico, de jogo, que se assemelha, : mas não se iguala, à noção de balanço defendida por : Norbert Elias. Para Elias o esporte ajuda a manter um : equilíbrio entre as tensões - geralmente proibidas : no dia-a-dia, pela crescente internalização de regras : e pressões externas - e a proteção ordenada contra : os ferimentos corporais. Em outras palavras, uma : combinação entre emoções e sua regulamentação. ${ }^{19}$ :

Há um ponto específico que parece não estar : contemplado nos esforços teóricos de DaMatta e Elias: " eles pouco problematizaram a questão da técnica, " sobretudo no que ela diz respeito a esporte. Os teóricos " da Nova Esquerda, por sua vez, ocuparam-se dela, mas : de maneira insuficiente, permanecendo, muitas vezes, : na crítica geral. As considerações que seguem : procuram, dentro das limitações desse trabalho, avançar um pouco na reflexão desse ponto central das : práticas esportivas e da vida humana em geral.

\section{CONSIDERAÇÕES SOBRE A QUESTÃO : DA TÉCNICA}

Em texto recente, que se refere a esta "polêmica" sobre o qual escrevo o presente trabalho, Valter Bracht referiu-se ao problema da técnica, colocando-a como um dos temas que geram equívocos/mal-entendidos na Educação Física/Ciências do Esporte.

Segundo escreve Bracht,

No caso da lógica do sistema esportivo, o rendimento almejado é o máximo, não o possível ou o ótimo, considerando as possibilidades individuais e dos " grupos. No sistema esportivo o próprio rendimento máximo tornou-se o objetivo a atingir. Desta forma, os meios (técnicos) alcançam grande centralidade neste sistema. Há um enorme investimento no desenvolvimento técnico que permitirá o máximo de rendimento que permitirá, por sua vez, sobrepujar o adversário. Esta lógica aparece já no processo de iniciação esportiva, de forma muitas vezes inconsciente. $^{20}$

Considero a questão da técnica muito importante, também quando ela se relaciona ao esporte, seja ele praticado nas escolas, nas pistas e quadras olímpicas, nos terrenos baldios, nas praças, ou nos hospitais psiquiátricos. Ela não é, evidentemente, importante apenas para o esporte, mas para a vida em geral, já que nos faz refletir sobre uma das características que justamente nos fazem humanos: a capacidade de produzir meios - técnicos ou tecnológicos - para alcançar fins. Em outras palavras, é pensando a questão da técnica que nos colocamos a ponto de refletir sobre os instrumentos que podem nos fazer viver melhor.

O tema ganha maior importância porque vivemos uma época na qual ele alcança importância ímpar na história. Não quero com isso dizer que em outros tempos a técnica não foi importante. O que a torna tão singular no mundo contemporâneo é sua onipresença, seu

papel na formação das subjetividades, incorporação, medida e critério, homens e mulheres.

Não por acaso, Theodor Adorno referiu-se à fetichização da técnica, seu caráter sinistro de ganhar, como que por obra de um feitiço, vida por $\begin{aligned} & \text { sua } \\ & \text { É na vida burocratizada, no } \\ & \text { amor canalizado para as } \\ & \text { máquinas e equipamentos, na } \\ & \text { tecnicficação do próprio corpo, } \\ & \text { na indiferença e na } \\ & \text { incapacidade de identificação, } \\ & \text { que reside o circulo demoníaco } \\ & \text { que desemboca na consciência } \\ & \text { reificada, incapaz de auto- } \\ & \text { reflexão, assim como no } \\ & \text { caráter manipulatório. }\end{aligned}$ própria em relação aos seres humanos. Em suas reflexões sobre o papel que deve a educação exercer para que a barbárie face sinistra do progresso e do curso da civilização não prevaleça, Adorno ocupa-se da fundamental questão da técnica, com a qual, como destaca, o esporte guarda forte correspondência:

Um mundo em que a técnica ocupa uma posição tão decisiva como acontece atualmente, gera pessoas tecnológicas, afinadas com a técnica. Isto tem sua racionalidade boa: em seu plano mais restrito elas serão menos influenciáveis, com as correspondentes conseqüências no plano geral. Por outro lado, na relação atual com a técnica existe algo de exagerado, irracional, patogênico. Isso se vincula ao 'véu tecnológico'. Os seres humanos inclinam-se a 


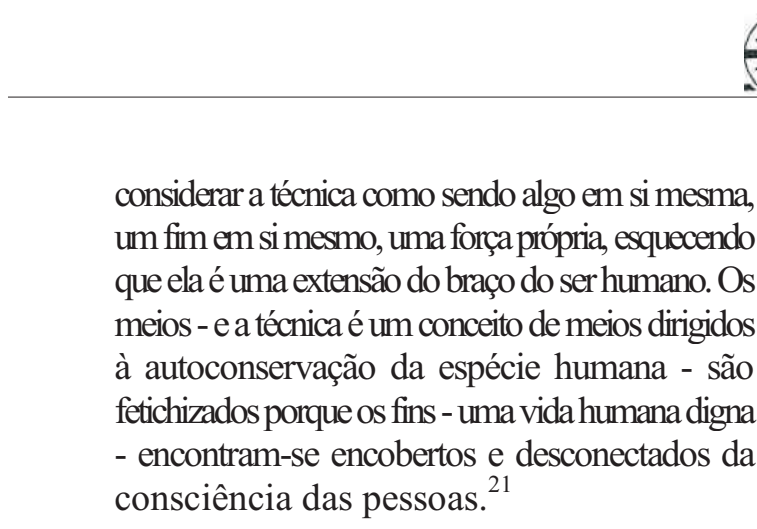

É na vida burocratizada, no amor canalizado para as máquinas e equipamentos, na tecnicficação do próprio corpo, na indiferença e na incapacidade de identificação, que reside o círculo demoníaco que desemboca na consciência reificada, incapaz de autoreflexão, assim como no caráter manipulatório.

Trata-se de refletir sobre o tipo de subjetividade

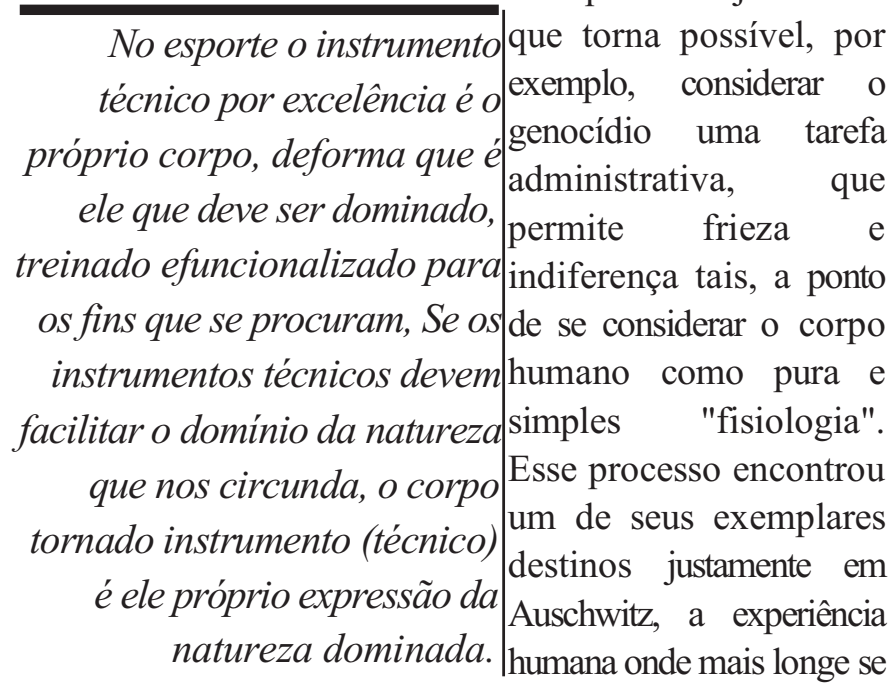
levou a racionalização, a cientificização e o : planejamento da barbárie. Paradoxalmente, essa fronteira do esclarecimento ${ }^{22}$ teve uma de suas faces mais sombrias justamente no tratamento racional, científico, como "assunto médico", ${ }^{23}$ de vários dos prisioneiros dos campos de concentração e : extermínio. $^{24}$

Lembre-se aqui, de passagem, uma das essenciais faces complementares da redução dos corpos à mera fisiologia: os Jogos Olímpicos, em particular os de 1936, em Berlin, concebidos como Obra de Arte Total (Gesammtkunstwerk). As Olimpíadas fazem parte do ideário neoclássico, restaurativo, vinculado a mitologização da Antigüidade. Nesse sentido, não foi difícil ao Nacional-Socialismo estabelecer, contra os corpos de judeus, ciganos, homossexuais e "deficientes", um paralelo entre a restauração dos mitos olímpicos gregos e os germânicos, vinculados também a um corpo ariano esportivizado, supostamente reconciliado com a natureza. ${ }^{25}$

Não é o caso de condenar a técnica em si, o que seria não mais que um contra-senso. Trata-se de criticarlhe em seu caráter de centralidade, não apenas quando aparece com inegável força, como no esporte de alto rendimento, mas também nos recônditos onde é capaz de sobreviver onipresente, quase clandestina, como imperativo a confirmar o espírito do próprio tempo.

\section{Técnica, Domínio do Corpo, Rendimento}

Como Bracht destacou, para qualquer atividade corporal com significado e sentido, é preciso dominar uma técnica, ou um conjunto de técnicas, como "movimentos aprendidos para realizar fins", havendo, no esporte, um enorme investimento nos meios (técnicos), com vistas ao máximo rendimento e à sobrepujança dos adversários. ${ }^{26}$ Gostaria de explorar um pouco essa idéia do investimento nos meios, na técnica, tentando identificar alguns dilemas e paradoxos que aí se circunscrevem.

O caso do esporte é paradigmático, porque as técnicas que desenvolvemos para ele são fundamentais para um melhor desempenho, fazendo com que dominemos melhor o próprio corpo em movimentos firmes e eficientes, às vezes surpreendentes, outra tantas admiráveis. Afirmo isso sobretudo por um motivo. No esporte o instrumento técnico por excelência é o próprio corpo, de forma que é ele que deve ser dominado, treinado e funcionalizado para os fins que se procuram. Se os instrumentos técnicos devem facilitar o domínio da natureza que nos circunda, o corpo tornado instrumento (técnico) é ele próprio expressão da natureza dominada.

São extensas as raízes que sustentam a possibilidade do corpo ter rendimento. A principal delas talvez seja a separação radical entre sujeito e objeto, princípio dos modelos tradicionais de ciência, das filosofias do sujeito, do cristianismo. Ela se afigura como separação 
entre uma esfera não corporal (Geisí) que exerce senhorio, e o corpo, próprio e o de outros, visto como objeto a ser conhecido e dominado. De alguma forma, a isso correspondente o processo que cinde o trabalho em corporal e intelectual. "E só a cultura que conhece o corpo como coisa que se pode possuir; foi só nela que ele se distinguiu do espírito, quintessência do poder e do comando, como objeto, coisa morta, 'corpus'."27 Problemático é que ao considerarmos nosso corpo como coisa, somos sujeito e objeto ao mesmo tempo, ou dito de outra forma, vítimas e algozes simultaneamente.

O rompimento com o mito e o desencantamento do mundo, que erigem o esclarecimento e formam a civilização, exigem não mais uma aproximação por assemelhamento com a natureza ou com as divindades, situação típica de uma relação mágica. Ao cindir-se da natureza, o ego torna-a objeto, para o qual a mediação par excellence é a razão subjetiva, expressa pelo trabalho, pela técnica e pela ciência.

A técnica efetua a adaptação ao inanimado a serviço da autoconservação, não mais como magia, através da imitação corporal da natureza externa, mas através da automatização dos processos espirituais, isto é, através de sua transformação em processos cegos. Com seu triunfo, as manifestações humanas tornamse ao mesmo tempo controláveis e compulsivas. ${ }^{28}$

O desejo de um rendimento cada vez mais alto no esporte é, por sua vez, acompanhado pela preocupação com uma precisão cada vez maior na análise, traduzida, via de regra, em linguagem matemática, em números que possam comparar grandezas em sua possível equivalência, o que sem dúvida altera a especificidade da experiência vivida. Construímos, é bom que se lembre, uma sociedade que ama os grandes números, as detalhadas estatísticas. Mais uma vez não se pode dizer que esta é uma tendência presente apenas no esporte, mas é possível facilmente perceber que ele aparece como uma vanguarda de um tipo de sociedade cujo Leitmotiv é fortemente vinculado à idéia de rendimento.

A preocupação com o rendimento traduzido em números, obedecendo à lógica do progresso quantificável, aparece em nossas diversas manifestações sobre fenômenos que, tecnificados, parecem perder sua qualidade intrínseca, seu conteúdo interno, degradados em números. Situação que, acrescentese, é bastante comum na linguagem e no pensamento economicista, tornado a lógica do dia a dia.

A tendência contemporânea a tudo explicar por determinações econômicas resulta de serem elas consideradas como um circuito fechado de fenômenos objetivos, cujas leis análogas àquelas sujeitas ao determinismo da natureza os homens devem se submeter. A linguagem econômica expressase, por sua vez, em números, fórmulas, estatísticas. Pensamento por média, pode ser assim entendido: "x come quatro sanduíches por dia; y nenhum. $\mathrm{Na}$ média o faminto come dois". A modernidade em sentido neoliberal é criptogenocida; opera com o raciocínio da sobrevivência, do limite entre a vida e a morte, quando os humanos têm resguardado apenas uma fina película que os liga ao mundo dos vivos. No modo de vida da contemporaneidade, os indicadores do progresso referem-se à 'vida primária'; referemse ao metabolismo basal - o consumo diário de calorias, proteínas, vitaminas, etc. Sabe-se que essa fórmula é aplicada ao cenário amargo de países africanos. No momento, o Brasil adota a 'africanização' como indício de modernização e progresso. O neoliberalismo é o capitalismo que perdeu todos os escrúpulos." 29

Note-se que essa linguagem matematizada é freqüentemente utilizada também no esporte, e que a África é modelo crescente para várias disciplinas atléticas, detendo, vários de seus atletas, expressivas marcas mundiais.

A questão, como fica claro, não se limita e não acaba no esporte, uma vez que o fascínio pela técnica e pelo progresso é uma das marcas recorrentes de nossa civilização. $\mathrm{O}$ esporte apenas radicaliza essa fascinação, reforçando a fé de que o progresso do corpo é infinito. Talvez isso aconteça porque o esporte tende a tornar tudo passível de mensuração, o que facilita a comparação objetiva, sem a qual a idéia de rendimento se tornaria inócua.

Em última análise, o esporte não pode prescindir nem do aparato técnico, nem do esforço em transformar o corpo em instrumento. 
Corpo e Maquinaria
Refinado crítico da modernidade, Theodor Adorno,
ocupou-se também do esporte. ${ }^{30}$ Para Adorno haveria
na constelação que se afigura no esporte, além de um
momento de ostentação à violência, do culto à
obediência, ao autoritarismo e ao sofrimento, a
presença de um aspecto masoquista. "Ao esporte
pertence não apenas o impulso à violência, mas
também a suportá-la e tolerá-la.."
Os dominados celebram a própria dominação. Eles
fazem da liberdade uma paródia, na medida em que
livremente se colocam a serviço da cisão, mais uma
vez, do indivíduo com seu próprio corpo. Por meio
dessa liberdade confirma-se a injustiça - fundada na
violência social - que mais uma vez se destina aos
corpos escravizados.

Funda-se aí a paixão pelo

Osporte, na qual os cadeiras de roda são imagens $\mid$ farejam o verdadeiro substrato que antecipam, que realizam para sua ditadura. É

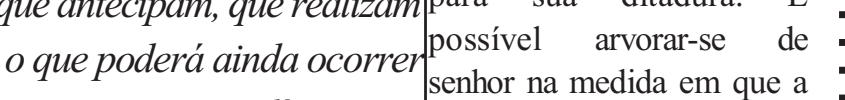
no esporte olímpico- $a$ senhor na medida em que a substituição de um órgão ou repetida, mais uma vez é membro por outro artificial, provocada em si mesmo e nos potencialmente melhor, ${ }^{\text {outros. }}{ }^{32}$ eletrônico, um braço, perna ou coração ciborgues, mais $\mid \begin{array}{lr}\text { Tratar-se-1a da } & \text { da } \\ \text { adação ao sempre }\end{array}$ precisos, mais controláveis. igual disfarçado de novo, da submissão ao

modelo industrial. O esporte pretenderia devolver ao corpo uma parte daquilo que lhe roubara a máquina, mas - pertencendo ao campo da não liberdade - o faz no sentido de colocá-lo implacavelmente a serviço da maquinaria, incorporando-se a sua lógica cega. ${ }^{33}$ Mimetizando a máquina, os seres humanos confundemse com ela, não se lhe afiguram mais "apenas" como apêndices, mas o são de si próprios, visto que a diferença entre ambos, na prática, desaparece. ${ }^{34}$

Não se trata, portanto, de simplesmente assemelhar o corpo à maquinaria, mas de "transformar" o próprio corpo em máquina, de forma que não se possa mais perceber a distinção entre ambos. Se é verdade que a lei do menor esforço exige que se deva desenvolver máquinas para acelerar, ${ }^{35}$ a maquinização do corpo se coloca então como estrutura que sustenta, justamente, a idéia de que é preciso acelerar cada vez mais: deve-se, no esporte, fazer o maior esforço, desde que ele signifique o maior rendimento. Fala-se, no mundo dos esportes, que uma "melhor" técnica serve para diminuir o esforço, mas na verdade seu objetivo é apenas aumentar o rendimento.

Enquanto o corpo no treinamento deve ser visto como objeto operacionalizável, as metáforas que o comparam a algum aparato maquinai são várias, desde a máquina a vapor até o relógio. ${ }^{36}$ Uma vez visto como máquina, pode ser "posto em funcionamento", ou "desligado", pode "estragar" e "ter suas peças trocadas". As próteses e transplantes indicam esse olhar. Os eventos esportivos em cadeiras de roda são imagens que antecipam, que realizam o que poderá ainda ocorrer no esporte olímpico: a substituição de um órgão ou membro por outro artificial, potencialmente melhor, eletrônico, um braço, perna ou coração ciborgues, mais precisos, mais controláveis. O uso de substâncias químicas, legais ou não, para melhoria da performance, é outro produto dessa lógica. Deve-se destacar, nesse contexto, as "drogas técnicas", que teriam como novidade o fato de serem capazes de rivalizar com as primeiras, sem que necessariamente os efeitos fisiológicos daquelas se façam notar. Refiro-me aqui à colonização do corpo por pequenos órgãos sintéticos. ${ }^{37}$

Lembre-se que uma "consciência mecânica do corpo" foi essencial não só para o desenvolvimento do esporte, mas de um pensamento de tipo esportivo, ${ }^{38}$ de uma sociedade esportivizada.

A indústria de máquinas e instrumentos utilizados para a melhoria da performance esportiva é muito forte, assim como é, especificamente, a dos aparelhos para a melhoria da condição fisica. Mas todo esse maquinário só faz sentido se o próprio corpo for observado como máquina. $\mathrm{O}$ instrumento já não é um prolongamento do corpo, nem mesmo um apêndice da máquina. Corpo e máquina, como disse acima, confundem-se, assemelham-se, igualam-se. Não só quando em estado patológico o corpo será visto como máquina, como se lê nas Mínima Moralia, ${ }^{09}$ mas, como maquinaria, ele sempre estará doente. 


\section{MIMESIS E TECHNÉ}

A Educação Física é responsável por grande parte das : técnicas corporais e dos cuidados com o corpo nos: ambientes educacionais. As aulas de Educação Física : - assim como muitas vezes os momentos de recreio : - constituem, sem dúvida, espaços privilegiados para : o ensino de um grande conjunto de técnicas corporais, : notadamente os esportes. Em face do conjunto de : dilemas e paradoxos que envolvem a questão da : técnica, especificamente no que toca ao esporte, cabe : perguntar como fica sua relação com a Educação Física : escolar,

É evidente que a escola não pode ignorar o esporte, : e, mais do que isso, deve tê-lo como conteúdo de : ensino. Ao ensinar o esporte, no entanto, ela não : deve deixar de considera-lo em suas múltiplas : dimensões, observando que o conhecimento a ser : trabalhado a partir do conteúdo esporte não pode : equiparar-se, simplesmente, ao aprendizado prático : das modalidades, nem às informações relativas às : regras e táticas de jogo.

Nesse sentido, em primeiro lugar, destaco que o: esporte e os outros elementos da cultura corporal : devem ser duplamente aprendidos: por um lado pela : mediação reflexiva sobre os temas relacionados ao : corpo e à corporeidade; por outro pelas dimensões : técnica e mimética, pela aproximação estética entre : sujeito e objeto. $^{40}$

Predico, portanto, uma educação que procure a razão : crítica e a mediação reflexiva (como negatividade), : mas também, com igual força, uma aproximação : sensível (einen sinnlichen Zugang), combinando, de : forma aconchegante, técnica e mímesis. Sem : desprezar, portanto, a espontaneidade ${ }^{41}$ e a dimensão : não conceituai $^{42}$ (porém não irracional!) do : conhecimento.

Seria preciso, portanto, valorizar o conteúdo de: verdade no esporte, sem esquecer seu estado de: inverdade, estruturado na fetichização da técnica, tornada um fim em si mesmo e muitas vezes : incorporada a partir dos ídolos de ocasião - situação : que interessa à manutenção da ordem de coisas, uma : vez eclipsada a capacidade reflexiva.
É por meio da técnica que se estabelecem os processos mais refinados de domínio, que expressam, por sua vez, a fé no progresso infinito e sem limites do corpo e dos resultados esportivos, expressões marcantes da razão instrumental. Exemplar é a relação que o esporte e a educação esportiva têm com a dor o sofrimento. No esporte exige-se o aprendizado da superação da dor, que não deve mais ser considerada como expressão irrenunciável da corporeidade. Para o esporte e a educação esportiva, a dor é uma sensação que deve ser ou superada ou tornada fonte de prazer. Em outras palavras, é necessário tornar-se indiferente à dor, a própria e a dos outros, ser duro consigo mesmo. ${ }^{43}$ E preciso, mesmo que paradoxalmente, tratar o corpo como um obstáculo a ser vencido, domado. ${ }^{44}$

O conteúdo de verdade do esporte pode, no entanto, ser encontrado na valorização do momento de reconhecimento do corpo, o próprio e o dos outros, não mais como domínio e progresso, mas como reconciliação. É preciso, nesse caso, estar atento ao
0 conteúdo de verdade do esporte pode, no entanto, ser encontrado na valorização do momento de reconhecimento do corpo, o próprio e o dos outros, não mais como domínio e progresso, mas como reconciliação. É preciso, nesse caso, estar atento ao reconhecimento dos limites e das fraquezas, as próprias e as dos outros, renunciando, portanto, à busca incessante do progresso.

\section{reconhecimento dos}

limites e das fraquezas, as próprias e as dos outros, renunciando, portanto, à busca incessante do progresso.

Não se trata, então, de uma denegação da técnica, mas de sua combinação reconciliatória com a mimesis, trazendo à consciência e à prática, para que possam ser superados, os momentos danificados intrínsecos ao esporte, mesmo lá, onde aparentemente tudo é calma e harmonia. Refiro-me aos momentos de "descontração", de "lazer", nos pátios, quadras e parques, onde a consciência danificada pelo fetiche da técnica muitas vezes permanece, de forma clandestina, na coletivização, na violência material e 
simbólica, nos rituais que entronizam a fungibilidade e a dor. Resta saber, no entanto, se seremos capazes de identificar e superar esses processos, tornados tão óbvios e "naturais" em nossa civilização.

\section{BIBLIOGRAFIA REFERENCIADA}

ADORNO, Theodor. Educação após Auschwitz. In: Educação e Emancipação. São Paulo/Rio de Janeiro, Paz e Terra, 1995.

. Erziehungnach Auschwitz. GesammelteSchriften. Frankfurt am Main: Suhrkamp, 1997a, vol. 10-2. . Veblens Angriff auf die Kultur. Gesammelte Scbriften. Frankfurt am Main: Suhrkamp, 1997b, vol. 10-1.

. Minima Moralia: Reflexionen aus derbeschädigten Leben. Gesammelte Scbriften. Frankfurt am Main: Suhrkamp, 1997c, vol. 4.

. Noten zur Literatur. Gesammelte Scbriften. Frankfurt am Main: Suhrkamp, 1997d, vol. 11.

ALMEIDA, M.J. de. A liturgia olímpica. In: SOARES, C. (Org.). Corpo e História. Campinas: Autores Associados, 2001.

ARENDT, H. Eichmann in Jerusalém-. A Report on the Banality of Evil. New York: Peguin, 1994.

BOGNER, A. Zivilisation und Rationalisierung. Opladen: Westdeutscher Verlag, 1989.

BRACHT, V. A criança que pratica esporte respeita as regras do jogo...capitalista. Revista Brasileira de Ciências do Esporte, São Paul, vol. 7, n. 2, p.62-68, 1986.

. Esporte-Estado-Sociedade. Revista Brasileira de Ciências do Esporte, Campinas, vol. 1, n. 2, p.6973,1989 .

Educação Física e aprendizagem social. Porto Alegre: Magister, 1992.

Esporte na escola e esporte de rendimento. Movimento, Porto Alegre, ano 6, n.12, p.XIV-XXrV, julho 2000.

BROHM, J-M. Sociologie politique du sport. In: BERTHAUD e col. Sport, culture etrépression. Paris François Maspero, 1976a.

. Sociologie poitique du sport. Paris: Jena-Pierre Delarge, 1976b.
Ink

. Sport: a Prision ofMeasured Time. London:

Links, 1978.

BUCK-MORSS, S. Review: Norbert Elias. The Civilization process. Telos, p. 180-198,1978.

_. Dialektik des Sehens: Walter Benjamin und das Passagen-Werk. Frankfurt: am Main: Suhrkamp, 1993.

BENJAMIN, W. (Nota a) Das Kunstwerk im Zeitalter seiner technischen Reproduzierbarkeit. Gesammelte Scbriften. Frankfurtam Main: Surhkamp, 1980.

CAVALCALTI, K. B. A função cultural do esporte e suas ambigüidades sociais. In: COSTA, L. P. Teoria e prática do esporte comunitário e de massa. Rio de Janeiro: Palestra, 1981.

. Esporte para todos: um discurso ideológico. São Paulo: Ibrasa, 1984.

CLAUSSEN, D. Grenzen der Aufklärung: Die gesellschaftliche Gênese des modernen Antisemitismus. Frankfurt am Main: Fischer, 1994.

COURTINE, Jean-Jacques. Os Stakhanovistas do Narcisismo: Body-buildinge puritanismo ostentatório na cultura americana do corpo. In: SANTANNA, Denise Bernuzzi (org.). Políticas do Corpo: Elementos para uma História das Práticas Corporais. São Paulo: Estação Liberdade, 1995.

DAMATTA, R. Carnaval, malandros e heróis: para uma sociologia do dilema brasileiro. Rio de Janeiro: Zahar, 1979.

. Esporte na sociedade: um ensaio sobre o futebol brasileiro. Universo do futebol. Rio de Janeiro: Pinakotek, 1982.

- Explorações: ensaios de sociologia interpretativa. Rio de Janeiro: Rocco, 1986.

. Antropologia do óbvio. São Paulo, Revista USP. n. 22, p. 10-17, jun/jul/ago 1994.

. Torre de babel. Rio de Janeiro: Rocco, 1996.

. Uma antropologia da sociedade brasileira: entrevista com Roberto DaMatta. Revista de Sociologia e Política, Curitiba, n. 10 e 11, p. 195211, 1998a. (Entrevista concedida a Marcos Lanna e Pedro Rodolfo Bodê de Moraes.)

. Vitória na Copa não terá dono. Jornal do Brasil, Rio de Janeiro p. 10, 14/junho/1998b. 
DUNNING, E. Sport Matters: sociological studies of sort, vilence and civilization. London/New York: Routledge, 1999.

ELIAS, N. Adorno-Rede: Respekt und Kritik. In: \& LEPENIS, W. Zwei Reden anlasslich der Verleihung des Theodor W. Adorno-Preises 1977. Frankfurt am Main: Suhrkamp, 1977.

. fiber den Prozess der Zivilisation. Frankfurt am Main: Suhrkamp, 1988.2. vol. . Die Gesellschaft der Individuen. Frankfurt am Main: Suhrkamp, 1991.

ELIAS, N. \& DUNNING, E. Quest for Exciting: Sport and Leisure in the Civilizing Process. Oxford \& New York: Basil Blackwell, 1986.

GEBAUER, G. Asthetische Erfahrung der Praxis. Das Mimetische im Sport. In: KONIG, E.; LUTZ, R (Org.). Bewegungskulturen: zu einer kritischen Anthropologic des Korpers. Akademia: Sankt Agustin, 1995. (Sport - Spiele - Kampfe).

GEBAUER, G. \& WULF, C. Mimesis: Kultur-KunstGesellschaft. Reinbek bei Hamburg: Rowohlt, 1992. . Spiel, Ritual, Geste: Mimetisches Handeln in der sozialen Welt. Reinbek bei Hamburg: Rowohlt, 1998.

GRUNEAU, R. The Critique of Sport in Modernity: Theorising Power, Culture and the Politics of the Body. In: DUNNING, E. G.; MAGUIRE, J. A; PEARTON, R. E. (ED.) The Sports Process: a Comparative and Developmental Approach. Champaign: Human Kinetics, 1993.

HARGREAVES, J. Sport, Power and Culture. Oxford: Polity, 1986.

HORKHEIMER, M \& ADORNO, T.W. Dialetica do Esclarecimento: fragmentos filosoficos . Rio de Janeiro: Zahar, 1985.

_. Dialektik der Aufklarung: Philosophische Fragmente. Gesammelte Schriften (Adorno). Frankfurt am Main: Suhrkamp, 1997a, vol. 3.

. Das Schema der Massenkultur (Dialektik der Aufklarung. Anhang). Gesammelte Schriften (Adorno). Frankfurt am Main: Suhrkamp, 1997b, vol. 3.

LENK, H. Pragmatische Vernunft. Philosophiezwuischen Wissenschaft und Praxis. Stuttgart: Reclam, 1979.
LEVER, J. Soccer: Opium of the Brazilian People. Transaction, n. 2, p. 34-43,1969.

LOVISOLO, H. Regras, esportes e capitalismo. In: Educação fisica: arte da mediação. Rio de Janeiro: Sprint, 1995.

MATOS, Olgaria. Formas modernas do atraso. Praga-. estudos marxistas. n. 7, marco 1999.

MORGAN, W.J. Adorno on Sport: The Case of the Fractured Dialectic. Theory and Society, n. 17, p. 813-838,1988.

. Leftist Theories of Sport: a Critique and Reconstruction. Urbana/Chicago: Universityof Illinois, 1994.

RABINBACH, Anson. The Human Motor. Energy, Fatigue, and the Origins of Modernity. Berkley/Los Angeles, University of California, 1992.

RICHTER, J. (Org.) Die vertrimmte Nation oder Sport in rechter Gesellschaft. Reinbek bei Hamburg: Rowohlt, 1972.

RIGAUER, B. Sport und Arbeit: Soziologische Zusammenhänge und Ideologische Implicationen. Frankfurt am Main: Suhrkamp, 1969.

. Leistungssport als Arbeitsleistung. Zur gesellschaftlichen Dialektik sportspezifischer Leistung. In: RICHTER, J. (Org.) Die vertrimmte Nation oder Sport in rechter Gesellschaft. Reinbek bei Hamburg: Rowohlt, 1972.

SCHMOLINSKY, G. (Org.). Leichtathetik. 10. ed. Berlim: Sportverlag, 1980.

. Atletismo. 3. ed. Lisboa: Estampa, 1992.

PROKOP, U. Soziologie der Olympischen Spiele: Sport und Kapitalismus. Miinchen: Karl Hansen, 1971.

RUTTEN, A. Sport-Ideologie - Kritische Theorie: Etapen einer unglücklichen Liebe. Frankfurt am Main: Peter Lang, 1988.

TAMBOER, J. Philosophic der Bewegungswissenschaft. Butbach e Griedel, Afra, 1994.

WILDMANN, D. Begehrte Korper. Konstruktion und Inszenierung des "arischen"Männerkorpers im "Drittenreich". Wiirzburg: Konigshausen \& Neumann, 1998.

- VAZ, A. F. Do culto a performance: esporte, corpo e rendimento. Revista Brasileira de Ciencias do 
Esporte, Florianópolis, vol. 21, n. 1, p.100-107, : setembro 1999a. (Caderno 2 dos Anais do XI * CONBRACE)

. Treinar o corpo, dominar a natureza: notas para : uma análise do esporte com base no treinamento : corporal. Cadernos Cedes (Org. de SOARES, CL.), " Campinas, ano XIX, n. 48, p.89-108, agosto 1999b.

. Dos fenômenos sociais e suas ambigüidades: comentários de Theodor W. Adorno sobre o Esporte. : Revista Brasileira de Ciências do Esporte, : Florianópolis, vol. 21, n. 1, setembro 1999c. (Caderno : 3 Anais do XI CONBRACE)

'___ . "O octogenário volta para casa, e é bem-vindo": Norbert Elias escreve sobre Theodor W. Adorno. Curitiba, VColóquio Internacional sobre o Processo " Civilizador. Anais..., p. 29, 2000a.

. Na constelação da destrutividade: o tema do esporte em Theodor W. Adorno e Max Horkheimer. Motus Corporis, Rio de Janeiro, v.7, n.1, p.65-108, : maio 2000 b.

. Memória e Progresso: sobre a presença do corpo : na arqueologia da modernidade em Walter Benjamin. " In: SOARES, C. (Org.). Corpo e História. Campinas: Autores Associados, 2001.

VINNAI, G. Fussball ais Ideologie. Frankfurt am Main: Europäische Verlagsanstalt, 1970.

VIRILIO, P. Os Motores da História (entrevista concedida * a Denise Bernuzzi de SantAnna e Hermetes Reis de " Araújo). In: de ARAÚJO, Hermetes Reis (org.). : Tecnociencia e Cultura-, ensaios sobre o tempo " presente. São Paulo, Estação Liberdade, 1998.

ZALUAR, A. O esporte na educação e na política pública. Campinas, Educação \& Sociedade, n. 38, p. 19-44, abril 1991.

_. Cidadãos não vão ao paraíso. São Paulo/Campinas: Escuta/Unicamp, 1994.

\section{NOTAS}

* Professor Assistente do Departamento de : Metodologia do Ensino do Centro de Educação da " Universidade Federal de Santa Catarina. Doutorando : na Faculdade de Ciências Humanas e Sociais da Universidade de Hannover, Alemanha, onde é bolsista da CAPES, com apoio do DAAD, da UFSC e da própria
Universitat Hannover.

1 . BRACHT (2000, XVI-XVII).

2 . Especificamente VAZ 1999a, mas também 1999b.

3. Considero, nos limites do presente trabalho, a Teoria Crítica do Esporte como um corpo teórico único. Há, no entanto, semelhanças e diferenças de enfoque entre BROHM (1976a, 1976b, 1978) e RIGAUER $(1969,1972)$, bem como entre outros teóricos que podem ser com eles, de alguma forma, alinhados (por exemplo, VINNAI 1970; PROKOP 1971; RICHTER 1972). Para um maior aprofundamento da temática, podem ser consultados, entre outros, HARGREAVES 1986; KIRSCH 1986; GRUNEAU 1993; MORGAN 1994; BRACHT 1997; DUNNING1999.

4 . LENK 1973a, 1973b, 1979.

5 . RIGAUER 1969,1972. Consultar também bibliografia referenciada na nota 3.

6. BROHM 1976a, 1976b, 1978. Consultar também bibliografia referenciada na nota 3.

${ }^{7}$.SCHMOLINSKY1980.

${ }^{8}$.SCHMOLINSKY 1992:18.

9. CAVALCANTI 1981, 1984; BRACHT 1986, 1999, 1992,

1997.

10. BRACHT (1997: 29, n. 15) observou o contraponto entre estas perspectivas, com destaque para os trabalhos de DAMATTA (1994) e ZALUAR (1994). Destaque-se ainda, nesse contexto, um outro trabalho de ZALUAR (1991) e as ponderações apresentadas por LOVISOLO (1995).

11. DAMATTA 1979, 1982, 1986, 1994, 1996, 1998a, $1998 b$.

12. Discuto a perspectiva formulada por DaMatta no texto O esporte como drama e o dilema brasileiro: futebol e sociedade brasileira nos escritos de Roberto DaMatta, que deverá ser apresentado no próximo Congresso Brasileiro de Ciências do Esporte, em Caxambu, outubro de 2001.

13 . LEVER1969.

14. DAMATTA 1986:101-120.

15. Sobre uma crítica do ponto de vista da Sociologia Figuracional à Teoria Crítica do Esporte, consultar os trabalhos de ELIAS \& DUNNIG (1986) e DUNNING (1999). Meu próprio trabalho de doutorado, que será defendido brevemente junto à Faculdade de Ciências Humanas e Sociais da Universidade de Hannover, Alemanha, discute, entre outras questões, a relação entre as análises de Elias e seus seguidores a respeito 
do esporte, e aquelas que foram elaboradas a partir dos

27. HORKHEIMER \& ADORNO 1985:217,1997:266.

marcos da Teoria Crítica da Escola de Frankfurt. Não posso aqui aprofundar essa questão, mas destaco que há uma diferença fundamental entre a posição ocupada pelo corpo entre as teorias da civilização de Norbert Elias e de Theodor W. Adorno. Esta diferença referese, certamente, à interpretação/incorporação teórica que fazem da Psicanálise e também ao papel que ambos atribuem à barbárie (ou descivilização) no processo da civilização. Sobre a relação entre Adorno e Elias, podem ser consultados, entre outros, ELIAS 1977; BUCKMORSS, 1978; BOGNER 1989; VAZ 2000a. ${ }^{16}$. DAMATTA 1979:199-200. ${ }^{17}$. ELIAS 1988,1991. ${ }^{18}$. ELIAS 1988,1991.

19. ELIAS \&DUNNING 1992.

20. BRACHT 2000, XVI-XVII.

21. ADORNO 1995:132-133; 1997a:685. Esta tradução brasileira está, por mim, ligeiramente modificada.

22. Valho-me aqui da expressão empregada singular livro de Detlev Claussen, Grenzen der Aufklärung: die Gesellschafliche Gênese des modemen Antisemitismus (CLAUSSEN 1994).

23. Como fez questão de destacar o advogado de defesa do julgamento de Adolf Eichmann (ARENDT1994: 6970).

24. Trabalho essa questão de forma mais detalhada em outro texto, apresentado no Colóquio Nacional Dialética Negativa, Estética, Educação, na UNIMEP, Piracicaba, em março de 2000. Deve aparecer publicado no próximo ano, em livro organizado por Bruno Pucci. 25 Um documento fundamental desse empreendimento é o filme oficial dos Jogos de 1936, o projeto Olympia, de Leni Riefenstahl. Ele foi produzido por uma empresa de propriedade da diretora e de seu irmão Heinz, fundada com o apoio do financiador do projeto, o Ministério de Esclarecimento Popular e Propaganda (Reichsministeriumfür Volksaujklärung und Propaganda - RMVP). São duas as partes do filme, Festa dos Povos (Festder Völker) e Festa da Beleza (Fest der Schönheit), nas quais se pode assistir várias seqüências que procuram mostrar os corpos dos esportistas e ginastas em vinculação com uma natureza "purificada", higienizadora e asséptica. Sobre o tema, consultar, entre outros, WILDMANN 1998, principalmente p. 27-34 e ALMEIDA 2001. ${ }^{26}$. BRACHT 2000, XVI-XVII.

28. HORKHEIMER \& ADORNO 1985:169;1997:205; também ADORNO 1997c 171.

29. MATOS 1999:66-67.

30. Sobre a as análises e comentários de Adorno sobre o esporte, podem ser consultados, entre outros MORGAN 1988; RÜTTEN 1988; VAZ 1999b, 1999c, 2000b.

31. ADORNO 1997b:79-80.

- 32. HORKHEIMER \& ADORNO 1997b:328.

33. ADORNO 1997b:79-80.

- 34 . O fascínio moderno pela técnica, também vinculada ao corpo, não escapou aos olhos de Walter Benjamin.

Tratei desse tema em trabalho recentemente publicado

(VAZ, 2001): "As Olimpíadas de Berlin/1936 - um dos

primeiros eventos de massa não apenas filmados, mas televisionados - seriam, conforme já notou Susan Buck-

Morss (1993), a contra-face das Exposés: enquanto em Paris, em 1937, seria visto o mais contemporâneo da indústria, da técnica, da comunicação e da energia, em uma palavra, do progresso, na Alemanha estariam, um ano antes, expostos os corpos fortalecidos (e maquinários, segundo penso). Fundamental para o esporte, segundo Benjamin, é seu caráter prescritivo, que subjugaria o comportamento humano a uma severa medição em segundos e centímetros, esquadrinhandoo como elementaridade física (BENJAMIN 1980)."

35. VIRILIO 1998:136.

36. TAMBOER 1994; RABINBACH 1995.

37. VIRILIO 1998:146-147.

38. COURTINE 1995:93.

39. ADORNO 1997c:60.

40. Baseio-me aqui em minhas considerações (VAZ 2000b) e nas de GEBAUER (1995) e GEBAUER \& WULF (1998).

41. ADORNO 1997d.

42. GEBAUER \& WULF 1992.

43. ADORNO $1997^{\mathrm{a}}$

- 44. Sobre o tema escrevi que "A grande questão da tolerância à dor e ao sofrimento relaciona-se com a possibilidade da crueldade - e com ela a violência e a obediência - ser mediada, controlada e prescrita de forma racional, científica. A afinidade com a tortura, uma das práticas mais hediondas já produzidas pela humanidade, e ainda bastante presente nos idas atuais, parece não ser apenas eletiva." (VAZ 1999b, p. 104). 